\title{
Analisis Derajat Ploidi dan Pengaruhnya Terhadap Variasi Ukuran Stomata dan Spora pada Adiantum raddianum
}

\author{
Lilih Khotim Perwati \\ Laboratorium Ekologi dan Biosistematik Jurusan Biologi FMIPA Undip \\ lieh_lilih@yahoo.com
}

\begin{abstract}
Polyploidy is a common phenomenon in plants, especially on the species of ferns. The objectives of this research are to find out the variation of the ploidy levels, to know the effects on the stomata index and size of stomata and spore in Adiantum raddianum. The materials used to conduct this observation of chromosomes number were made from root tips or young leaf tips (croziers). The modified squash method was used in microscopic preparation. The result of the observation showed that there was a variation in ploidy levels from $2 \mathrm{n}=2 \mathrm{x}$ (diploid) to $2 \mathrm{n}=7 \mathrm{x}$ (septaploid). It appeared to be general trend that the higher level the ploidy causes the lower the index stomata but the bigger the stomata and the spore size.
\end{abstract}

Key word: Adiantum, poliploid, stomata, spora

\section{PENDAHULUAN}

Marga Adiantum terdiri kurang lebih 200 jenis, mempunyai bentuk daun yang beraneka ragam serta daerah distribusi yang luas. Di pulau Jawa menurut Backer (1939) tersebar luas dari Jawa Barat - Jawa Timur pada ketinggian $250-$ 2000 m.dpl. Kurang lebih 20 jenis telah dibudidayakan sebagai tanaman hias.

Poliploidi merupakan gejala yang umum dan tersebar luas dalam tumbuhan (Wang et al., 2007). Berbagai spesies paku dan tumbuhan berbunga terdapat sebagai sitotipe poliploid (Chen et al., 2009). Tumbuhan poliploid pada Pteridophyta kurang lebih 95\% (Quintanilla \& Escudero, 2006). Pada marga Adiantum berkisar 56,5 \% (Bidin, 1983), bahkan Perwati (2001) mencatat tumbuhan poliploid pada Adiantum sebanyak 96,7\% dari 61 sitotipe. Variasi derajat ploidi yang ditemukan adalah $2 \mathrm{x}$ (diploid) sampai dengan 7x (septaploid). Chen et al. (2009) menyatakan bahwa peristiwa poliploidisasi pada paku dan tumbuhan berbunga merupakan mekanisme evolusioner yang penting pada taksa tumbuhan.

Pengaruh poliploidi pada berbagai kelompok tumbuhan bervariasi, tetapi ada satu akibat dari poliploidi yang tetap adalah adanya penambahan ukuran sel (Stebbins, 1971). Polyploidy berhubungan dengan perubahan densitas dan ukuran stomata (Chen, 2009, \& de
Oliveira et al., 2004). Walker (1979) menyatakan bahwa ukuran stomata dan spora cenderung meningkat pada tumbuhan paku poliploid.

Sejumlah penelitian telah dilakukan terhadap penambahan ukuran sel pada beberapa tumbuhan poliploid. Diantaranya adalah pada Diplazium (Praptosuwiryo \& Darnaedi, 1994), Betulla papyrifera (Li et al., 1996), Euphorbia dulcis (Murgia et al., 1987). Perwati (2002) telah mencatat bahwa terdapat variasi derajat ploidi pada marga Adiantum.

Adiantum raddianum merupakan salah satu spesies tumbuhan paku yang tumbuh dari dataran rendah sampai dengan dataran tinggi. Jenis ini juga sudah dibudidayakan sebagai tanaman hias. Sejumlah penelitian jenis - jenis Adiantum talah dilakukan, tetapi baru sebatas pada kekayaan jenis. Data yang memuat tentang variasi jumlah kromosom (derajat ploidi) dan bagaimana pengaruhnya terhadap ukuran sel belum banyak ditemukan. Berdasarkan hal tersebut maka perlu dilakukan penelitian lebih lanjut mengenai variasi jumlah kromosom (derajat ploidi) dan pengaruhnya terhadap ukuran spora, stomata dan indeks stomata khususnya pada spesis Adiantum raddianum.

Adapun tujuan dari penelitian ini adalah untuk mengetahui variasi jumlah kromosom (derajat ploidi) dan pengaruhnya terhadap ukuran spora, stomata dan indeks stomata pada spesis Adiantum raddianum. 


\section{BAHAN DAN METODE}

Bahan penelitian berasal dari lereng selatan gunung Merapi pada ketinggian $200-1000$ m.dpl., Lereng selatan gunung Lawu pada ketinggian 1000 - 2100 m.dpl. dan Dataran tinggi Dieng 2000 - 2200 m.dpl. Contoh tumbuhan dibungkus kertas koran dan dibasahi air untuk menjaga kelembaban.

Tumbuhan yang diperoleh ditanam dalam pot, untuk mendapatkan ujung akar dan pucuk daun (crozier) baru dalam pengamatan jumlah kromosom. Setiap pot diberi label kode koleksi. Setiap koleksi diambil contoh spora dan daun untuk pengamatan ukuran spora dan stomata.

\section{a. Pengamatan jumlah kromosom}

Pembuatan sediaan untuk pengamatan kromosom menggunakan metode squash semi permanen menurut Jahier et al. (1996) yang dimodofikasi. Ujung akar dan pucuk daun muda (crozier) direndam larutan kolkhisin $0,05 \%$ pada temperatur $5^{\circ} \mathrm{C}$ selama dua jam. Bahan difiksasi dengan larutan farmer's pada temperatur $5^{\circ} \mathrm{C}$ selama 24 jam. Kemudian dihidrolisis menggunakan $\mathrm{HCl} 1 \mathrm{~N}$ pada temperatur $60^{\circ} \mathrm{C}$ selama 10 menit. Pewarnaan menggunakan larutan carbolic fuchsin selama 24 jam. Bahan diletakkan di atas gelas benda yang ditetesi gliserin dan aseto orcein $1 \%$. Gelas benda ditutup dengan gelas penutup, kemudian diketuk-ketuk menggunakan ujung kuas tumpul, lalu ditekan menggunakan ujung ibu jari. Pengamatan dan penghitungan jumlah kromosom dilakukan mengunakan mikroskop cahaya pada perbesaran 1000x. Menurut Wagner, 1963 penentuan derajat ploidi pada marga Adiantum berdasarkan jumlah kromosom dasar $\mathrm{x}=30$.

\section{b. Pengamatan spora}

Pembuatan sediaan mikroskopi untuk pengamatan spora menggunakan metode asetolisis menurut Feagri \& Iverssen (1989). Spora difiksasi menggunakan asam asetat glacial selama 24 jam, selanjutnya disentrifuge. Asam asetat glacial diganti larutan campuran asam asetat glacial dan asam sulfat pekat (9:1) dan dipanaskan dalam waterbath. Larutan diganti aquades dan disentrifuge. Kemudian diwarnai menggunakan safranin $1 \%$. Selanjutnya didehidrasi menggunakan tersier butil alkohol (TBA). TBA diganti minyak silicon sebagai media. Diambil satu tetes diletakkan di atas gelas benda dan ditutup menggunakan gelas penutup. Selanjutnya spora diamati menggunakan mikroskop cahaya, diukur panjang aksis polar dan ekuatorialnya menggunakan mikrometer.

\section{c. Pengamatan stomata.}

Pengamatan stomata menggunakan metode clearing techniques, menurut Prakash (1986) yang dimodifikasi. Potongan anak daun dimasukkan ke dalam tabung berisi kloralhidrat. Tabung dipanasi dalam air mendidih hingga potongan daun menjadi transparan. Potongan anak daun diletakkan di atas gelas benda dengan media gliserin. Selanjutnya diamati menggunakan mikroskop cahaya. Pada saat pengamatan diukur panjang serta lebar stomata menggunakan micrometer dan dihitung indeks stomatanya.

\section{HASIL DAN PEMBAHASAN \\ Klasifikasi \& Deskripsi}

Adiantum raddianum termasuk dalam divisi Filicophyta, kelas Leptosprangiopsida, familia Adiantaceae (Holtum, 1965; Gifford \& Foster 1989). Adapun deskripsi dari Adiantum raddianum adalah sebagai berikut: Perawakan: herba, berumpun rapat, melengkung. Batang: berupa rhizome, pendek, menjalar, bersisik, coklat gelap, bulat telur - lanset. Tangkai daun: silinder, coklat kehitaman, gundul, panjang 11,8 - 29,0 cm. Daun: majemuk, menyirip rangkap $3-5$, bentuk helaian daun segitiga - delta, panjang 5,6-23,3 cm, lebar 4,3 - 20,0 cm; pucuk daun hijau muda kemerahan. Anak daun: bentuk baji - kipas, jajaran genjang, panjang $0,2-1,9 \mathrm{~cm}$, lebar $0,2-1,5 \mathrm{~cm}$; tepi berlekuk - bergigi, tepi atas terbelah menjadi 2-4 lobus; tekstur lunak, gundul, warna hijau. Sorus: di bawah lipatan daun yang menggulung (indusium palsu), bentuk ginjal. Spora: trilete, tetrahedral, panjang sumbu polar $24.16-43.75 \mu \mathrm{m}$, sumbu ekuatorial $35.62-56.25 \mu \mathrm{m}$, ukuran sedang - besar, P/E 0,71 - 0.93, bentuk oblat subspheroidal. Stomata: anomositik, panjang 26.62 - $40.40 \mu \mathrm{m}$, lebar 24.87 - $32.75 \mu \mathrm{m}, \mathrm{p} / \mathrm{l} 0,95$ 1,37, indeks stomata $12.50-28.57$. Jumlah kromosom $2 n=60$ (diploid), $2 n=94,96$ (triploid), $2 \mathrm{n}=114,116,120$ (tetraploid), $2 \mathrm{n}=146$ (pentaploid), $2 \mathrm{n}=183$ (heksaploid), $2 \mathrm{n}=210$ (septaploid). Tipe reproduksi: seksual, apogami. 
Habitat: tanah, tanah berbatu, tumbuh alami di ketinggian 600 - 2200 m.dpl. di lereng Merapi, Lawu, dataran tinggi Dieng.

\section{Poliploidi}

Berdasarkan hasil pengamatan Wagner (1963) yang menyatakan bahwa jumlah bilangan dasar kromosom (x) pada marga Adiantum adalah 29 dan 30, dan yang paling umum terdapat dalam marga ini adalah $\mathrm{x}=30$. Dari hasil pengamatan (tabel 1) memperlihatkan bahwa koleksi Adiantum raddianum mempunyai derajat ploidi $2 x$ (diploid) dan poliploid. Hasil penghitungan jumlah kromosom dari 29 koleksi tumbuhan yang diamati menunjukkan variasi jumlah kromosom yaitu $2 \mathrm{n}=$ 60, 94, 96, 114, 116, 120, 146, 183, 210. Berdasarkan jumlah bilangan dasarnya maka derajat ploidinya berturut-turut adalah $2 \mathrm{x}$ (diploid), 3x (triploid), 4x (tetraploid), 5x (pentaploid), 6x (heksaploid) dan 7x (septaploid).

Tabel 1. Variasi jumlah kromosom (derajat ploidi) Adiantum raddianum

Tabel 1. Variasi jumlah kromosom (derajat ploidi) Adiantum raddianum

\begin{tabular}{lllc}
\hline $\begin{array}{c}\text { No Jumlah kromosom } \\
\text { (2n) \& derajat } \\
\text { ploidi (x) }\end{array}$ & $\begin{array}{l}\text { Lokasi/ jumlah } \\
\text { individu }\end{array}$ & $\begin{array}{c}\text { Ketinggian } \\
\text { tempat } \\
\text { (mdpl.) }\end{array}$ \\
\hline 1. $60(2 \mathrm{x})$ & M (1) & $800-1000$ \\
2. $94,96(3 \mathrm{x})$ & M(4), L(5),D (1) $600-2200$ \\
3. $114,116,120(4 \mathrm{x})$ & L (7), D (3) & $1000-2200$ \\
4. $146(5 \mathrm{x})$ & $\mathrm{M} \mathrm{(1),} \mathrm{L} \mathrm{(1)}$ & $800-1200$ \\
5. $183(6 \mathrm{x})$ & $\mathrm{M} \mathrm{(1),} \mathrm{L} \mathrm{(1)}$ & $800-1800$ \\
6. $210(7 \mathrm{x})$ & M (3), L (1) & $600-2000$
\end{tabular}

Keterangan: $\mathrm{M}=$ lereng selatan Merapi, $\mathrm{L}=$ lereng selatan Lawu \& D = dataran tinggi Dieng

Sebagian besar individu memperlihatkan pengurangan ataupun penambahan jumlah kromosom (aneuploidi/ euploidi). Berdasarkan bilangan dasar kromosomnya $\mathrm{x}=30$, seharusnya individu triploid mempunyai jumlah kromosom $2 \mathrm{n}=90,4 \mathrm{x}$ (tetraploid) $2 \mathrm{n}=120,5 \mathrm{x}$ (pentaploid) $2 \mathrm{n}=150$ dan 6x (heksaploid) $2 \mathrm{n}=180$. Banyaknya individu aneuploidi yang ditemukan mendukung penelitian Bidin (1983) yang juga menemukan frekuensi yang melimpah pada marga Adiantum. Menurut Jacas (1996) terdapatnya seri aneuploidi menunjukkan adanya kecenderungan evolusi pada tumbuhan.
Selama penggandaan genom peristiwa aneuploidi lebih sering terjadi pada jenis poliploid. Jenis poliploid lebih toleran dalam kehilangan kromosom. Kehilangan kromosom tidak merugikan pertumbuhan sel, sebab keseluruhan set dari gen tetap terdapat dalam genome (Briggs \& Walters, 1997; Lerner, 1999).

Jika dilihat dari distribusinya menunjukkan bahwa tumbuhan poliploid mempunyai distribusi yang lebih luas dari pada yang diploid dan sangat terkait dengan faktor ketinggian tempat. Tumbuhan diploid hanya ditemukan di lereng Selatan Merapi pada ketinggian 800 - 1000 m.dpl., sedangkan tumbuhan poliploid ditemukan di ketiga lokasi penelitian pada ketinggian 600 - 2200 m.dpl. Tumbuhan poliploid juga lebih banyak ditemukan daripada tumbuhan diploid. Briggs \& Walters, 1997 menyatakan bahwa tumbuhan poliploid lebih mampu berkoloni di daerah baru dan tahan terhadap habitat yang berbeda dengan tumbuhan diploidnya.

Meningkatnya peristiwa poliploidi dan teradaptasinya tumbuhan berderajat ploidi tinggi pada daerah yang berelevasi tinggi diduga karena turunnya temperatur. Sesuai dengan hipotesis Love \& Love (dalam Stuessy, 1990) yang menyatakan bahwa temperatur dan faktor lingkungan lain yang terkait dengan ketinggian tempat berperan dalam poliploidisasi tumbuhan.

\section{Ukuran Spora dan Stomata}

Pengamatan panjang sumbu polar dan equatorial spora, indeks stomata, panjang dan lebar stomata pada seri derajat ploidi dari diploid $(2 \mathrm{x})$ sampai dengan septaploid (7x) Adiantum raddianum yang terdapat di lereng Merapi, Lawu, dataran tinggi Dieng; hasilnya ditabulasikan dalam tabel 2. 
Tabel 2. Ukuran Spora dan Stomata pada berbagai derajat ploidi Adiantum raddianum

\begin{tabular}{|c|c|c|c|c|c|c|}
\hline \multirow{2}{*}{$\begin{array}{c}\text { Derajat } \\
\text { Ploidi }\end{array}$} & \multicolumn{3}{|c|}{ Spora } & \multicolumn{3}{c|}{ Stomata } \\
\cline { 2 - 7 } & $\begin{array}{c}\text { Polar } \\
\mu \mathrm{m})\end{array}$ & $\begin{array}{c}\text { Equator } \\
\text { ial }(\mu \mathrm{m})\end{array}$ & $\begin{array}{c}\text { Polar/ } \\
\text { Equator } \\
\text { ial }\end{array}$ & $\begin{array}{c}\text { Panjang } \\
(\mu \mathrm{m})\end{array}$ & $\begin{array}{c}\text { Lebar } \\
(\mu \mathrm{m})\end{array}$ & $\begin{array}{c}\text { Indeks } \\
\text { stomata }\end{array}$ \\
\hline $2 \mathrm{x}$ & 29.58 & 35.62 & 0.83 & 27.83 & 24.90 & 24.03 \\
$3 \mathrm{x}$ & 33.89 & 41.50 & 0.84 & 29.13 & 26.32 & 23.43 \\
$4 \mathrm{x}$ & 35.63 & 45.19 & 0.82 & 30.88 & 27.75 & 22.93 \\
$5 \mathrm{x}$ & 35.00 & 49.16 & 0.75 & 35.36 & 30.04 & 22.92 \\
$6 \mathrm{x}$ & 38.13 & 50.21 & 0.79 & 37.21 & 31.48 & 20.24 \\
$7 \mathrm{x}$ & 42.18 & 52.87 & 0.78 & 38.04 & 31.74 & 13.99 \\
\hline
\end{tabular}

Persamaan regresi kecenderungan ukuran spora dan stomata terhadap derajat ploidi berturut-turut disajikan dalam gambar $1 \& 2$.

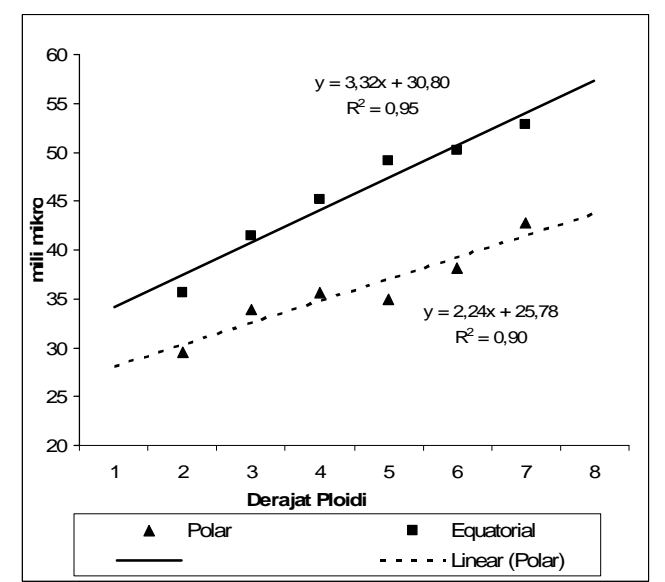

Gambar.1.Kecenderungan ukuran spora terhadap derajat ploidi

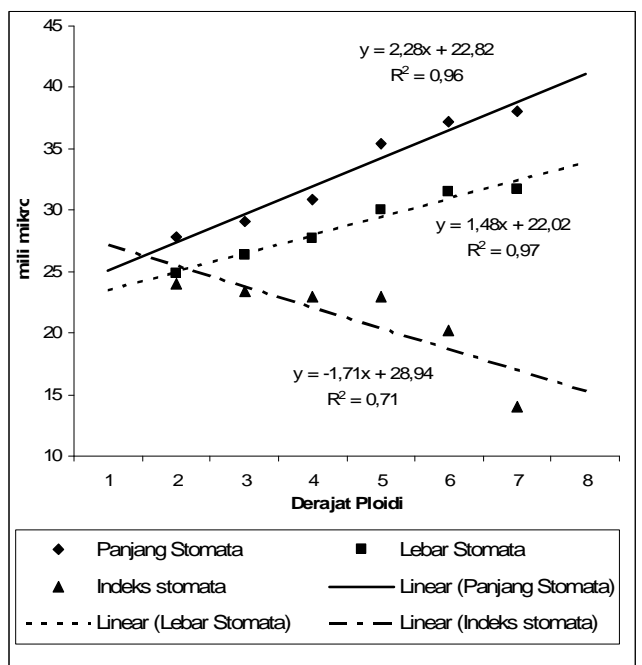

Gambar.2.Kecenderungan ukuran dan indeks stomata terhadap derajat ploidi.
Berdasarkan hasil pengamatan ukuran spora terlihat bahwa panjang sumbu polar \& equatorial mempunyai kecenderungan yang meningkat seiring dengan peningkatan derajat ploidi. Adanya peningkatan derajat ploidi akan diikuti pula ukuran sporanya. Pada pandangan polar mempunyai persamaan regresi $\mathrm{Y}=2,24 \mathrm{x}+25,78$ dengan $\mathrm{R}^{2}=$ 0,90 dan pada pandangan equatorial persamaan regresinya adalah: $\mathrm{Y}=3,32 \mathrm{x}+30,80$ dengan $\mathrm{R}^{2}=$ 0,95 . Perbandingan sumbu polar dan equatorial (bentuk) spora relatif tetap seiring dengan meningkatnya derajat ploidi.

Demikian juga pengaruhnya terhadap panjang dan lebar stomata, ada kecenderungan penambahan ukuran stomata seiring dengan peningkatan derajat ploidi. Pengaruh derajat plodi terhadap panjang stomata dapat dinyatakan dalam persamaan regresi linier $\mathrm{Y}=2,28 \mathrm{x}+22,82$ dengan $\mathrm{R}^{2}=0,96$. Pada pengamatan lebar stomata juga menunjukkan hal yang sama. Pengaruh derajat ploidi terhadap lebar stomata adalah $\mathrm{Y}=1,48 \mathrm{x}+$ 22,02 dengan $R^{2}=0,97$. Sedangkan pengaruhnya terhadap indeks stomata memperlihatkan bahwa indeks stomata semakin menurun dengan meningkatnya derajat ploidi. Kecenderungan tersebut dinyatakan dengan persamaan regresi $\mathrm{Y}=$ $-1,71 \mathrm{x}+28,94$ dengan $\mathrm{R}^{2}=0,71$.

Dari semua parameter yang diamati menunjukkan bahwa poliploidi menyebabkan penambahan ukuran sel. Bertambahnya ukuran sel merupakan refleksi dari bertambahnya ukuran vakuola dan kandungan air yang semakin banyak.

Keanekaragaman genetik yang tinggi dari tumbuhan poliploid berkontribusi terhadap kisaran distribusi dan variasi morfologi serta perbedaan habitat. Tumbuhan poliploid cenderung berhasil menginvasi suatu wilayah. Kemampuan poliploid dalam menginvasi habitat baru tergantung pada sifat baru dari morfologi dan fisiologi yang menyertai proses poliploidi tersebut.

Berdasarkan hasil penelitian Perwati (2002) memperlihatkan bahwa Adiantum poliploid mempunyai distribusi yang lebih luas dari tumbuhan diploid, dan di tempat yang berelevasi lebih tinggi tumbuhan poliploid lebih banyak ditemukan. Menurut $\mathrm{Li}$ et al, 1996 perubahan morfologi dan mekanisme fisiologi pada tumbuhan poliploid merupakan bentuk adaptasi terhadap lingkungan di tempat yang berelevasi tinggi. 
Adanya sifat morfologi dan fisiologi yang khas dari tumbuhan poliploid sangat menunjang kelangsungan hidup di habitatnya. Secara morfologi Adiantum radianum yang poliploid mempunyai indeks stomata yang lebih sedikit tetapi mempunyai ukuran stomata yang lebih besar dari pada tumbuhan yang diploid. Stomata adalah salah satu faktor penentu yang mempengaruhi efisiensi penggunaan air. Stomata yang lebar lebih lambat merespon terhadap dehidrasi. Hal tersebut merupakan struktur dasar dalam mengurangi kehilangan air dari daun. Pengaturan turgor merupakan adaptasi penting dari tumbuhan untuk menanggulangi kekurangan air.

\section{KESIMPULAN}

Tedapat variasi derajat ploidi dari diploid $2 \mathrm{n}=2 \mathrm{x}$ (diploid) sampai dengan $2 \mathrm{n}=7 \mathrm{x}$ (septaploid) pada Adiantum raddianum yang tumbuh di lereng selatan gunung Merapi dan Lawu serta dataran tinggi Dieng. Secara umun terdapat kecenderungan penambahan ukuran stomata dan spora seiring dengan peningkatan derajat ploidi, tetapi semakin menurun indeks stomatanya.

\section{UCAPAN TERIMA KASIH}

Terima kasih kepada semua pihak yang telah membantu penyelesaian penelitian sampai dengan dipublikasikannya hasil penelitian ini.

\section{DAFTAR PUSTAKA}

Backer, C.A. \& O. Posthumus. 1939. Varenflora Voor Java. Uitgave Van`s Lands Plantentuin Buitenzorg, Java. p. 164-170.

Bidin, A. 1983. Penelitian Sitologi pada Genus Adiantum L. (Adiantaceae). Sains Malaysiana 12 (4): 275-286.

Briggs, D. \& S.M. Walters. 1997. Plant Variation and Evolution. 3rd. ed. Cambridge University Press.

Chen, G; W.B. Sun \& H. Sun, 2009. Morphological characteristics of leaf epidermis and size variation of leaf, flower and fruit in different ploidy levels in Buddeleja macrostacya (Buddlejaceae).
Journal of Systematics and Evolution 47 (3): $231-236$ (2009)

de Oliveira V. M., E R. Forni-Martins, P. M. Magalhães and M.N. Alves, 2004. Chromosomal and morphological studies of diploid and polyploid cytotypes of Stevia rebaudiana (Bertoni) Bertoni (Eupatorieae, Asteraceae). Genetics and Molecular Biology, 27, 2, 215-222 (2004).

Feagri, K. \& J. Iversen. 1989. Textbook of Pollen Analysis. Hafner Press. New York.

Gifford, E.M. \& A.S. Foster. 1989. Morphology and Evolution of Vascular Plants. third ed. W.H.Freeman and Company, New York.

Jahier, J; A.M. Cherve; R. Delourme; F. Eber \& A.M. Tangui. 1996. Techniques of Plant Cytogenetics. Science Pub Inc. USA. p. 156.

Jacas, N.G; A.R. Susanna, \& Ilarslan, 1996. Aneuploidy in the Centaureinae (Compositae). American Journal of Botany 83 (10): 1356-1364.

Lerner, H.R. 1999. Plant Responses to Environmrntal stresses: From Phytohormones to Genome Reorganization. Marcel Dekker, Inc.New York.

Li, W.L; G.P. Berlyn \& P.M.S. Ashton, 1996. Polyploids and Their Structural and Physiological Characteristics relative to Water Deficit in Betula papyrifera (Betulaceae). American Journal of Botany. 83 (1) : 15-20.

Murgia, M; H.J.Wilms \& M. Cresti, 1987. Ultrastructural Comparison of Pollen Grains from 2n, 3n and 4n Plants of Euphorbia dulcis. American Journal of Botany. 74 (11): 1665-1671.

Perwati, L.K.,Santosa, Purnomo 2002. Sitotaksonomi Marga Adiatum di Gunung Merapi, Lawu dan Dataran Tinggi Dieng. Teknosains, Vol. 15, No. 2, Mei 2002: 379 390.

Perwati, L.K., 2002. Sitogeografi Marga Adiantum L. di Gunung Merapi dan Lawu. Biosfera, Vol 19 (3) September 2002. 65 - 69.

Prakash, N. 1986. Methods in Plant Microtechnique. 2 nd. Departement of Botany, The University of New England. 
Praptosuwiryo, N. \& D. Darnaedi. 1994. Cytological Study of the Fern Genus Diplazium in Gunung Gede-Pangrango National Park, Java. Floribunda 1 (15): $57-$ 60 .

Quintanilla, L. \& A. Escudero, 2006. Spore Fitness Components Do Not Differ Between Diploid and Allotetraploid Species of Dryopteris (Dryopteridaceae). Annals of Botany 2006 98(3):609-618.

Stebbins, G.L. 1971. Chromosomal Evolution in Higher Plants. Adison Wesley Publishing Company.

Stuessy, T.F. 1990. Plant Taxonomy, The Systematic Evaluation of Comparative
Data. Columbia Univ. Press, New York. p. 291-311.

Wagner, Jr.W.H. 1963. A Biosystematic Survey of United States Ferns. American Fern Journal 53 (1): 1-16.

Walker, T.G. 1979. The Cytogenetics of Ferns. dalam A.F.Dyer (ed.). The Experimental Biology of Ferns. Academic Press, London. p. 87-123.

Wang, Y., X. Chen, C-B. Xiang, 2007. Stomatal Density and Bio-water Saving. Journal of Integrative Plant Biology 2007, 49 (10): $1435-1444$ 